from the tumour cells is provided by Amatruda, Mulrow, Gallagher and Sawyer (1963). So far as one is aware this association has not been seen in the reticuloses, although Plimpton \& Gellhorn, (1956), have reported hypercalcaemia (also probably endocrine in origin) in one case of Hodgkin's disease.

In all the cases in the present series, Hodgkin's disease was histologically proven. In each case the serum sodium level was at some time 125 $\mathrm{mEq} / 1$. or below. This hyponatraemia was associated with a low serum osmolality with a ratio of urine-to-serum osmotic pressure greater than one. There was, therefore, good evidence of inappropriate secretion of $\mathrm{ADH}$. The absence of clinical disturbance associated with the hyponatraemia is also in favour of a dilutional hyponatraemia rather than an Addisonian type, and this was suggested in Case 1 by the fall in serum specific gravity in parallel with sodium. This was confirmed by studies of total body fluids and exchangeable electrolytes. In each case the total exchangeable sodium was in the normal range, but the total body water was increased in volume.

Rees, Rosalki and Maclean (1960) and Ross (1963), also described hyponatraemia in carcinoma of the bronchus associated with increased renal loss of sodium. This was thought to be the result of a proximal renal tubular lesion, since aminoaciduria, glycosuria and phosphaturia were also present. None of our cases had excess aminoacids or glucose in the urine. Moreover, in Rees' case there was evidence of dehydration rather than overhydration. In the patients discussed here there was no evidence of adrenal failure, although one had hypoplasia of the adrenal cortex at post mortem. This was thought to be consistent with long term steroid therapy.
It seems, therefore, that inappropriate secretion of ADH can oocur in Hodgkin's disease. It would be of interest to attempt extraction of the antidiuretic sbstance from the affected nodes and spleen.

I would like to thank Dr. Joan Zilva and Dr. K. A. Newton for their great help and encouragement with the preparation of this paper. I would also like to thank Mr. T. M. Prossor and Mr. E. Stanley Lee for allowing me to use cases under their care and Dr. Ledingham for his co-operation, Mrs. J. Watson for technical assistance and Mrs. M. Chatfield for secretarial help.

This work has been done whilst receiving a fulltime research grant from the British Empire Cancer Campaign.

\section{REFERENCES}

Amatruda, Jr., T. T., Mulrow, P. J., Gallagher, J. C., and SAwYeR, W. H. (1963): Carcinoma of the Lung with Inappropriate Anti-diuresis (Demonstration of Anti-diuretic Hormone-like Activity in Tumour Extract), New Engl. J. Med., 269, 11, 544.

Plimpton, C. H., and Gellhorn, A. (1956): Hypercalcaemia in Malignant Disease without Evidence of Bone Destruction, Amer. J. Med., 21, 750.

Rees, J. R., Rosalki, S. B., and Maclean, A. D. W. (1960): Hyponatraemia and Impaired Renal Tubular Function with Carcinoma of the Bronchus, Lancet, ii, 1005.

Ross, E. J. (1963): Hyponatraemic Syndromes Associated with Carcinoma of the Bronchus, Quart. J. Med., 32, 297.

Schwartz, W. B. Bennett, W., Curelop, S., and BARTTER, F. C. (1957): A Syndrome of Renal Sodium Loss and Hyponatraemia Probably Resulting from Inappropriate Secretion of Anti-diuretic Hormone, Amer J. Med., 23, 529.

\title{
A CASE OF THROMBOCYTHAEMIA WITH RED CELL APLASIA
}

\author{
A. J. E. Brafield, M.B., M.C. Path., \\ Consultant Pathologist \\ Julian Verbov, M.B., M.R.C.P., \\ Medical Registrar
}

Whipps Cross Hos pital, London, E.11

ESSENTIAL thrombocythaemia and pure red cell anaemia are rare conditions. That they should occur in the same patient is of special interest.

\section{Case Report}

Mrs. F. P., aged 76, a known case of neurosyphilis, was admitted on 1st October, 1965, with a history of weight loss for six months, passing fresh blood per rectum more recently, and loss of appetite for a week or so. She had suffered with classical lightning pains in her lower limbs for five years.

On examination she was pale, thin and blind. A triple rhythm was audible over the lower end of the sternum, and heart rhythm was regular. There were signs of collapse over her left lung base. No 
abnormality was found on abdominal palpation, and rectal examination was normal. ONS:-bilateral optic atrophy and absenoe of pain sensation in the tendo achillis on pressure. Hb $5.8 \mathrm{~g} / 100 \mathrm{ml}$., ESR $40 \mathrm{~mm} / \mathrm{hr}$., WBC $19,500 / \mathrm{cu}$. mm. (polys $81 \%$, lymphs $12 \%$, monos $7 \%$ ), blood film showed moderate hypochromia and anisocytosis, and an apparent increase in platelets. Blood urea $34 \mathrm{mg} / 100 \mathrm{ml}$. Serum Wassermann and V.D.R.L. tests negative. Urine examination was normal. Chest radiograph was reported as showing extensive shadowing in the left base due to collapse and pleural effusion, but at chest aspiration on 13th October no fluid was obtained. Repeated stool examinations were positive for oocult blood. Sigmoidoscopy on 115 th October revealed no abnormality up to $12 \mathrm{~cm}$. Incomplete barium swallow and meal on 8th October showed no organic lesion in loesophagus, stomach or duodenum, and barium enema on 26 th October was normal.

Haemoglobin, rechecked prior to treatment on 5th Ootober was $7.0 \mathrm{~g} / 100 \mathrm{ml}$. and itreatment was commenced with oral ferrous gluconate $5 \mathrm{gr}$. three times daily. On 19th October the haemoglobin level was unaltered and marrow puncture produced a moderately cellular specimen showing a striking paucity of red cell precursors (L: E ratio $30: 1$ ) with early normoblasts $0.5 \%$, intermediate $1.5 \%$ and late normoblasts $1.5 \%$. No pronormoblasts were found. There was little demonstrable iron, either extracellular or intracellular. Segmented polymorphs were $60 \%$, megakaryocytes $1 \%$, and platelets were present in large numbers. Serum iron was $33 \mu \mathrm{g} /$ $100 \mathrm{ml}$. Parenteral iron (Jectofer-iron sorbitol citric acid complex) was commenced on 22nd October. There was little haematological response, the maximum reticulocyte being $5.2 \%$ on 5 th November, and on 10th November the haemoglobin level remained unaltered. A repeat marrow punoture on 12th November showed no alteration whatever from the earlier specimen, the $L: E$ ratio remaining at $30: 1$ with very few normoblasts and no pronormoblasts seen. The leucocyte count, repeated several times during this period climbed slowly to $28,000 / \mathrm{cu}$. $\mathrm{mm}$. with $88 \%$ fully segmented polymorphs. Repeated platelet counts gave values between 650,000 and $865,000 / \mathrm{cu}$. mm.

Other Investigations: Serum haptoglobins normal. Ham's test for acid haemolysis negative. Urine for haemosiderin negative.

She remained quite well until late October when her condition began to deteriorate. She was apyrexial throughout and passed no overt blood per rectum during her stay. It was noticed on 25 th Ootober that many of her superficial upper limb veins were thrombosed. Lightning pains continued throughout her illness and seemed to be relieved by paracetamol tablets. She died quietly on 14 th November.

Necropsy revealed evidence of old neurosyphilis, chronic gastric ulceration, and a malignant growth which arose from the left lower lobe bronchus, spread through the diaphragm and had almost completely destroyed the spleen. No thymic tissue was found. Histologically, the tumour was a squamous celled (sometimes anaplastic) carcinoma. The vertebral marrow was moderately cellular with absence of the usual foci of erythropoiesis, these cells being distributed only diffusely, and in reduced numbers. Megakaryocytic hyperplasia was prominent. No areas of extra-medullary myelopoiesis were found in other organs.

\section{Discussion}

Haemorrhagic (essential) thrombocythaemia and pure red cell anaemia have each been separately described in association with a variety of conditions, and there is room for argument whether either exists as a primary disorder. Essential thrombocythaemia would usually seem to be a manifestation of the myeloproliferative syndrome. Pure red cell anaemia is most characteristically associated with benign thymoma but has been described in Kiwashiorkor, in toxic, allergic and infective conditions, and as a result of bone marrow damage by blood group antibodies.

The simultaneous presence in this case, of thrombocythaemia, neutrophil leucocytosis and anaemia of hypoplastic type is difficult to explain. Chronic haemorrhage from a peptic ulcer or carcinomatosis offer possible though unsatisfactory explanations. The presence of many morphologically atypical platelets, the absence of immature polymonphs, together with a history of unexplained fresh bleeding per rectum and thrombotic episodes is very suggestive of essential thrombocythaemia. It is unfortunate that the patient died before coagulation tests were carried out, though defective platelet funotion has not always been present in the recorded cases of otherwise typical essential thrombocythaemia. The low serum iron together with the patient's social circumstances would suggest malnutrition as a cause of the anaemia, as in Kwashiorkoo (Foy, Kondi and MacDougall, 1961). Chronie. iron deficiency of itself would be unlikely cause erythroid hypoplasia. The only preparation the patient took regularly before admission was Tab. Codein. Co. (Aspirin, phenacetin and codein) Finally, the role of the spleen should be considered. Ablation of splenic function is known to produce thrombocythaemia, and splenic atrophy or absence was found in several of the cases of haemorrhagic thrombocythaemia reviewed by Hardisty and Wolff (1955). Any possible association with hypoplastic anaemia appears unlikely, although splenic atrophy has been frequently described in Fanconi's syndrome of congenital pancytopenia. It seems at least possible therefore, that the almost complete destruction of the spleen by malignant growth might in some way have accounted for the very unusual blood picture.

We are grateful to Dr. H. Wykeham Balme for $\frac{D}{0}$ permission to publish this case.

\section{REFERENCES}

FoY, H., Kondi, A., and MacDougall, L. (1961): Pure Red-Cell Aplasia in Marasmus and Kwashiorkor treated with Riboflavine, Brit. med. J., i, 937.

HARDISTY, R. M., and WolfF, H. H. (1955): Haemorrhagic Thrombocythaemia: A Clinical and Laboratory Study, Brit. J. Haemat, 1, 390.

\section{.}

